\title{
NANOMATERIALS AS TISSUE ADHESIVES
}

\author{
I. Ceren Yasa, Hakan Ceylan, Ayse B. Tekinay, \\ AND Mustafa O. Guler \\ Institute of Materials Science and Nanotechnology, National Nanotechnology \\ Research Center (UNAM), Bilkent University, Ankara, Turkey
}

\subsection{INTRODUCTION}

Tissue adhesives are used to create functional bonding interfaces between injured tissue parts and between tissues and implanted biomaterials. Wound closure and biointegration of prosthetics or synthetic tissue constructs are the major applications within this context (Annabi et al., 2014; Lauto et al., 2008; Meddahi-Pellé et al., 2014; Sharma et al., 2013). Hemostats, which are used to stop bleeding, and sealants, which are used to create an interfacial barrier against air or fluid, can also be considered along the line of tissue adhesive concept as they essentially require in vivo bonding and biointerface formation. Skin adhesives have also become an emerging concept for sensory applications, particularly in real-time healthcare monitoring (Kwak et al., 2011).

Millions of patients across the developed and developing countries suffer from wounds or surgical incisions that need proper closure followed by accelerated healing and tissue regeneration (Annabi et al., 2014; Bre et al., 2013; Sanders and Nagatomi, 2014). These wounds and incisions mainly

Therapeutic Nanomaterials, First Edition. Edited by Mustafa O. Guler and Ayse B. Tekinay.

(C) 2016 John Wiley \& Sons, Inc. Published 2016 by John Wiley \& Sons, Inc. 
include skin and the underlying tissues, such as connective tissues, muscles, and tendons, which have limited regeneration capacity. Currently, there are several medically approved options for bonding tissue parts. The global share of adhesive market shows that surgical sutures and other mechanical bonding methods dominate the market despite their poor efficiencies, particularly in compliant and inaccessible tissues, particularly laparoscopic procedures, in addition to their invasive application and considerable toxicity and hypersensitivity risks (Annabi et al., 2014; Bre et al., 2013). Moreover, in some cases, suturing can impair the tissue healing (Bre et al., 2013). Sutures also fall short to stop the leakage of body fluids. Further, application of surgical sutures requires extensive expertise in the level of surgeons. Alternative bonding methods relying on mechanical interlocking and staples also present risks of damaging the surrounding tissues and the vasculature (Yang et al., 2013). On the other hand, ease of application of a glue substance, in principle, should significantly broaden the use of such types of materials in various types of medical and surgical applications. Tissue adhesives can be applied over the wound or incision site, act as hemostats or sealants, create an antimicrobial barrier, and can even induce proper tissue regeneration. In light of these perspectives, recent studies estimate that medical adhesives will increase their portion in the market by 2017 (Report S190, 2012). Therefore, the efforts in this field have focused on the development of new medical adhesives and improving the existing ones in accordance with defined design principles. A typical tissue adhesive for wound healing should fulfill certain criteria to find wide applicability in medical and surgical practices (Bouten et al., 2014; Páez et al., 2004):

1. Biocompatibility and biodegradability, including both the adhesive and its degradation products

2. Ease of administration

3. Timely functioning, optimized curing kinetics

4. Sufficient mechanical strength for the desired application, an optimal balance of cohesiveness and adhesiveness of the material underwater

5. Low degree of swelling

6. Long shelf life and stability

7. Cost-effectiveness

Depending on the surgical procedure, the characteristics of the adhesives might vary. In bleeding, for example, tissue parts approximated via an adhesive interface is also expected to function as a hemostatic agent. On the other hand, improvement in one parameter usually comes with a trade-off. 
For example, when the adhesion strength is increased, toxicity becomes intolerably high (Lauto et al., 2008). Consequently, optimizing individual parameters while preserving the overall material performance in a dedicated medical or surgical procedure is the gold standard.

Another major application of tissue adhesives is the mechanically stable and biocompatible integration of foreign biomaterials, such as metal prosthetics or synthetic soft tissue constructs, into the sites of implantation (Gittens et al., 2014; Sharma et al., 2013). In this regard, the biochemical nature of the bonding surface of a foreign biomaterial is of utmost significance for the long-term effectiveness of the surgical intervention. Once the implant is placed, a foreign body reaction is raised by the immune system that works to isolate and remove the material from the body. An ideal adhesive, therefore, should create an interface that bond the biomaterial to the tissue while it is recognized as self in the body and functional tissue will grow on it. In order to overcome this challenge, strong underwater adhesives should also be able to modulate cellular activities through biologically active signals (Avila et al., 2009; Liu et al., 2006; Richards et al., 2012). A state-of-the-art research in this field concentrates on developing hybrid systems that consist of a base adhesive recapitulating the cellular microenvironments by mimicking the architecture and biology of the extracellular matrix of the tissue of interest (Ceylan et al., 2011, 2014; Kang et al., 2012; Sharma et al., 2013).

Adhesion in vivo presents considerable challenges arising mainly from the aqueous and dynamic chemistry of the living environment. Highly polar water molecules and polyionic species interact both with the surface and the adhesive molecules, thereby interfering with the adhesion process. Based on the source of the raw material and inspiration of the design, technologically available tissue adhesives can be categorized as natural, synthetic, and bioinspired. Most of the efforts for designing and manufacturing of tissue adhesives have been on curable functional polymers and derivatives of natural adhesives. Synthetic adhesives have strong mechanical properties, yet low degradation rate and cytotoxic by-products upon degradation restrict their clinical application (Agarwal et al., 2007). Although natural adhesives including fibrin glues and collagen-based products are effective in adhesion, their availability is limited due to autologous isolation from tissue. Moreover, they often have weak tensile and adhesive strength (Kull et al., 2009), which is critical for long-term adhesion. In this regard, nanoenabled materials, such as nanoparticles, and bioinspired synthetic designs promise opportunities to produce new types of tissue adhesives with superior characteristics. In this chapter, we provide a critical review of the conventional tissue adhesive materials and their shortcomings. We then concentrate on the design approaches of 
emerging tissue adhesive technologies, particularly those using nanotechnology, with a primary focus on their clinical applicability.

\subsection{TISSUE ADHESIVES BASED ON SYNTHETIC POLYMERS}

Various classes of synthetic polymers have been developed and applied as tissue adhesives. Their defined chemistry and tailorable material properties, such as adhesion strength, curing kinetics, and mechanical properties, drove the motivation in this approach. The two major classes of synthetic tissue adhesives discussed in this chapter are acrylate-based adhesives and polyurethanes. Typically, synthetic polymer-based tissue adhesives are characterized by high mechanical properties, fast curing time, poor biocompatibility, and moderate tissue adhesion strength.

Traditional and commonly used synthetic adhesives are acrylic adhesives and urethane-based ones. Acrylic adhesives are based on polymerization of acrylate and methacrylate monomers (Fig. 8.1a) by a hardener or free radical initiators to cure with time, heat, or ionizing radiation. The main properties

(a)<smiles>[R]OC(=O)C(=C)C#N</smiles>

(ii)<smiles>[R2]OC(=O)C=C</smiles><smiles>[R]C(C)(C)CCC(CCCCC)C(C)CCCCC</smiles><smiles>[R][Y]([H])([H])C</smiles>

(b)

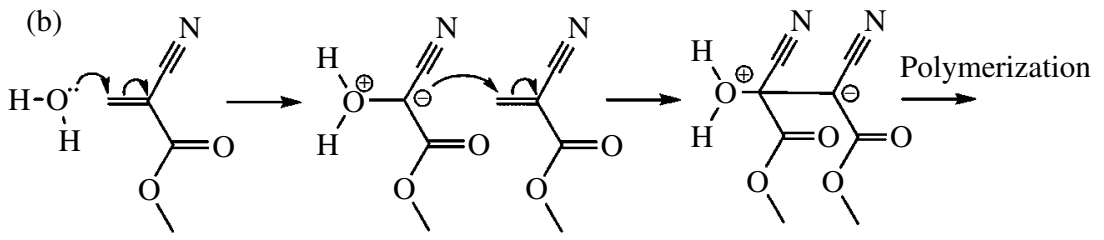

(c)

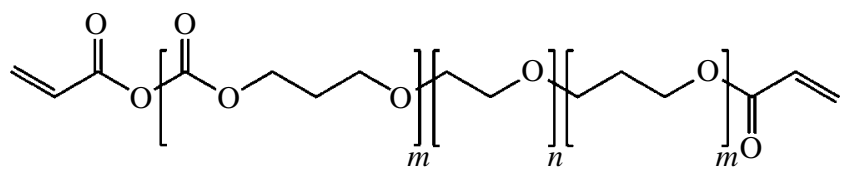

FIGURE 8.1 Cyanoacrylate and acrylate-containing adhesives. (a) Monomeric units of cyanoacrylates (i) and acrylates (ii) used as tissue adhesives. (b) Anionic polymerization (curing) of methyl cyanoacrylate in the presence of water. (c) Chemical structure of $\mathrm{PTMC}_{m}-\mathrm{PEG}_{m}-\mathrm{PTMC}_{m}$ diacrylate adhesive. 
of acrylics, which make them ideal for developing adhesives, are their ability to make bond with many substrates, controllable rate of cure, appropriate strength, simplicity in use, and low degree of toxicity (Lees, 1979). Cyanoacrylates and acrylic polyethylene glycol (PEG) derivatives are commonly used acrylic materials to develop adhesives.

Cyanoacrylate-based adhesives have been used to assist in wound management, and they are also popular in dentistry for bonding orthodontic brackets and repairing dentures. What makes them one of the primary choices of synthetic adhesive materials is their adhesive properties including strong adhesion, rapid curing time, instantaneous adhesion to tissue, and ease of use (Leggat et al., 2004; Trott, 1997).

Cyanoacrylate monomers including methyl cyanoacrylate, ethyl cyanoacrylate, $n$-butyl cyanoacrylate, and 2-octyl cyanoacrylate form polycyanoacrylates by polymerization reaction (Singer et al., 2008). Double bond in the acrylate is important for the polymerization of this glue. In principle, susceptibility of electron-withdrawing nitrile group to nucleophilic attack by weak bases causes rapid polymerization upon contact with water or blood (Fig. 8.1b). After initiation by water, the monomers polymerize via anionic polymerization (Bouten et al., 2014; Seewald et al., 2002), and adhesion of tissue is accomplished via formation of covalent bonds between the cyanoacrylate and functional groups in the tissue proteins, such as primary amines of the lysine side chains (Bouten et al., 2014). However, these polymers can degrade and result in accumulation of the degradation products in tissue, which causes histotoxic hypoxia. Therefore, the use of the short side chain and methyl and ethyl cyanoacrylates is mostly abandoned due to such side effects (Trott, 1997).

Chemical adhesives, including cyanoacrylate, adhere strongly to tissues by a reactive exothermic covalent cross-linking reaction. These adhesives may suffer from desired time for adhesion event and may release toxic chemicals such as formaldehyde, which can cause an inflammatory response (Vote and Elder, 2000) within ca. 8 weeks of degradation period. Despite these drawbacks, due to fast polymerization and strong adhesion, cyanoacrylate tissue adhesives have been approved in Canada and Europe, and several products are commercially available, such as Dermabond, Histoacryl, IFAbond, and Omnex (Bhatia, 2010) since the 1980s.

These cyanoacrylate adhesives have been used in various clinical applications including gastric variceal bleeding, esophageal variceal bleeding, peptic ulcer bleeding, and closure of fistula (Maluf et al., 2001; Ryan et al., 2004; Ryou and Thompson, 2006). Also closure of smooth and fresh skin wounds and endoscopic incisions are another indicated applications. 
PEG polymers and its acrylic derivatives are also used for tissue adhesion. PEG-based tissue adhesives consist of chemically functionalized linear or branched PEG molecules, which can be cross-linked either by chemical cross-linking or photo-cross-linking, depending on available chemical groups. To be cross-linked through irradiation and form an adhesive hydrogel, PEGs should be modified with photoreactive elements such as acrylate groups (Mehdizadeh and Yang, 2013). Due to this modifiable chemistry of PEGs, the adhesion mechanism in PEG-based systems presents high variability; therefore, it is dependent on the formulation (Shazly et al., 2008). FocalSeal-L (Genzyme Biosurgery, Inc., Cambridge, Massachusetts) is the FDA-approved product in this category, which is a photopolymerizable adhesive based on self-assembly principle. Basically, as a primary solution, PEG-PLA polymer is used due to its low viscosity and applied to tissue, after which PTMC-PEG polymer (Fig. 8.1c), the sealant solution, is added and polymerized using irradiation in the presence of a photoinitiator (Bouten et al., 2014; Reece et al., 2001). Cross-links between the acrylate groups of the polymers result in the formation of hydrogel. However, application of the compound is difficult and nearly impossible in hemorrhage situations due to photoactivation requirement. In order to get rid of same activation sources, similar products are being developed. One such PEG polymer, CoSeal (Cohesion Technologies, Inc., Palo Alto, CA), consists of two PEG polymers that rapidly cross-link with proteins in tissue and mechanically adhere to synthetic graft materials. CoSeal is being used in Europe and it provides both cardiac adhesion prevention and anastomotic sealing. It is also indicated for reinforcement of suture and staple lines that can effectively cover and adhere to areas, which could be the source of an air leak around a lung resection (Napoleone et al., 2009). The main disadvantages of this system are its high degree of swelling after application and its weak adhesion to the surrounding tissue (Bhatia, 2010).

Another FDA-approved PEG sealant is Duraseal, which consists of PEG ester and trilysine amine solutions. Mixing of these two components results in the formation of a nontoxic hydrogel with 3D network due to cross-linking of PEG molecules by trilysine. It is used for closure of cerebrospinal fluid (CSF) leakage following neurosurgery (Spotnitz and Burks, 2008). PEG polymers are also used in combination with a chondroitin sulfate and resulting biodegradable CS-PEG hydrogels provide covalent adhesion to tissue (Strehin et al., 2010). For PEG-based systems, biodegradation takes 4-12 weeks (Lauto et al., 2008).

Another type of synthetic tissue adhesive material is urethane. Urethanebased adhesives have also been considered for use as soft tissue adhesives or sealants, because of their thermal stability at physiological temperature and absence of hemolytic behavior (Ferreira et al., 2007). Possible biocompatibility and biodegradability as well as the ability to form urea linkages through reaction 
(a) Urethane-based

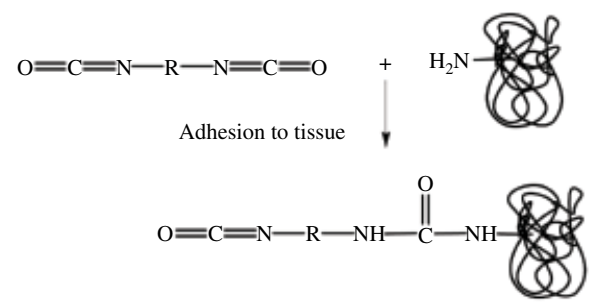

(b)

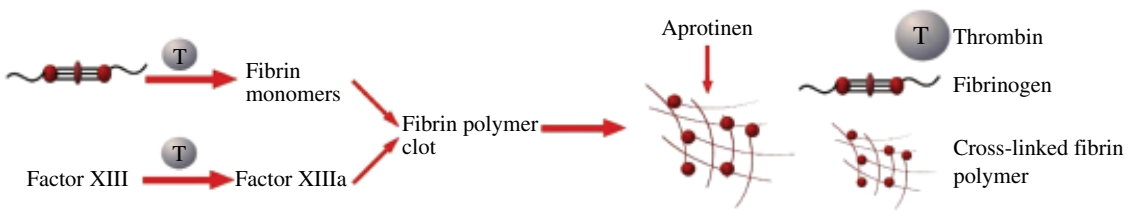

(c)
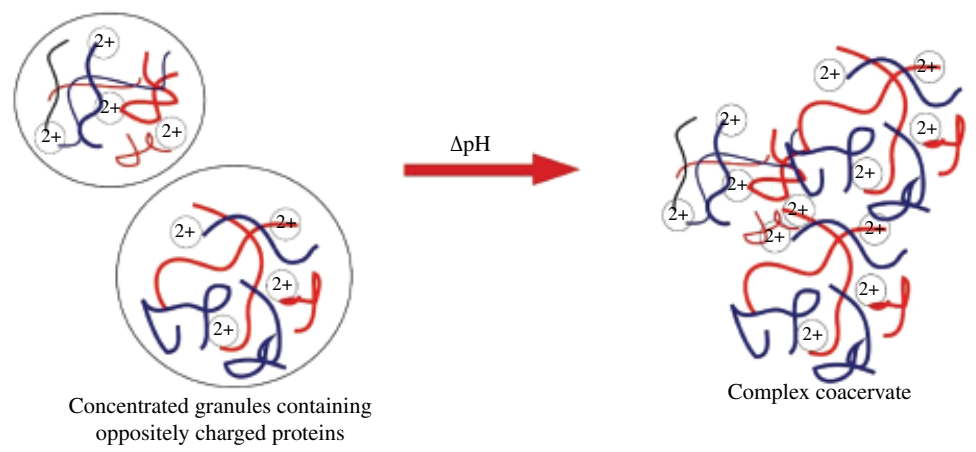

FIGURE 8.2 Mechanism of (a) adhesion of urethane-based adhesives through reacting with amine groups of proteins and water, (b) cross-linked fibrin curing, and (c) schematic illustration of complex coacervation.

with the amino groups present in the biological molecules are the main properties of the urethane-based adhesives that make them appealing candidates.

In order to synthesize urethane-based tissue adhesives, aromatic and aliphatic polyisocyanates with different polyether/polyester diols have been used in recent decades. Isocyanate groups have affinity to nucleophilic attack by hydroxyl or amine groups. As such, reaction of isocyanate-terminated prepolymer with amine groups in tissue proteins and formation of urea bond result in tissue adhesion, while cross-linking occurs through reacting with water in the tissue, summarized in Figure 8.2a (Mehdizadeh and Yang, 2013). 
Polyurethanes are formed through polyaddition reaction between diisocyanates and diol groups. By virtue of their adhesion mechanism, urethane-based sealants were tested in renal surgery, endocrinology, and pancreatic occlusion and no toxic effects were observed (Bre et al., 2013). They are also being used for bone fixation, hemostasis, and sealing of vascular grafts in several surgical procedures (Heiss et al., 2006).

TissuGlu $^{\circledR}$ surgical adhesive is one of the commercially available urethane-based products used for abdominal tissue bonding. It consists of a hyperbranched polymer with isocyanate end groups containing about $50 \mathrm{wt} \%$ of lysine (Gilbert et al., 2008). In the presence of moisture in the tissue, cross-linking occurs with itself and with the tissue surface, which forms a strong bond between layers. This adhesive can be degraded through hydrolysis and enzymatic reactions in the lysine linkages. The degradation products are usually polyols (e.g., glycerol), lysine, ethanol, and carbon dioxide, which are water soluble and easily cleared from the body (Gilbert et al., 2008).

\subsection{NATURALLY DERIVED TISSUE ADHESIVES}

Although many biological organisms produce their own adhesive materials that hold the above criteria, synthetic materials that have been developed so far do not fulfill all the requirements. Tissue adhesives developed based on naturally available sources benefit from inherent biocompatibility. In addition, structural and biochemical signals mimicking the native extracellular matrix could accelerate tissue regeneration (Annabi et al., 2014). On the other hand, high production cost, limited material availability, and potential immunogenicity are the major factors that hinder their wide range of use in medical and surgical operations.

Fibrin-based glues are most widely used natural tissue adhesives in clinical applications, and their use as local hemostatic agents was first reported in as early as 1910s (Leggat et al., 2004). Fibrin glues act similar to the last stage of blood clotting, where fibrinogen is converted to fibrin clot through a complex coagulation cascade. It creates a deliverable clot for use as both a hemostatic and a sealant. The fibrin sealants consist of two components: thrombin in combination with calcium chloride solution and fibrinogen (together with factor XIII and some other blood plasma proteins) (Brennan, 1991). Thrombin converts fibrinogen to fibrin monomers and activates factor XIII to factor XIIIa in the presence of calcium chloride. Then factor XIIIa cross-links fibrin molecules by the formation of amide bonds and stabilizes the polymeric network. 
In a broad range of clinical applications, fibrin glues have been utilized for mainly control of bleeding and leaking after surgeries (Wheat and Wolf, 2009). TISSEEL is an approved fibrin family sealant produced to be used in patients undergoing surgery when conventional surgical methods are impractical for hemostasis. In some case studies, it was reported to be used for closure of esophageal perforations (Mutignani et al., 2006) and gastrocutaneous fistulae after gastrostomy tube removal (Rabago et al., 2002). Fibrin glue is also used to fix skin grafts in plastic and reconstructive surgery. Crosseal ${ }^{\mathrm{TM}}$ is the human protein, bovine component-free fibrin sealant, which reduces ecchymoses and hematoma formation in rhytidectomy patients efficiently (Lee et al., 2009b). Other commercial fibrin glues include Beriplast, Biocol, and Tissucol, which are intended to be used for hemorrhage, wound healing, and tissue gluing (Currie et al., 2001). Biodegradation of fibrin glues currently used in clinical procedures takes 2 weeks.

Despite of having many advantages, autologous isolation from tissue limits the availability of fibrin and makes fibrin glues relatively expensive. There are also some safety concerns regarding the use of thrombin from bovine sources, including allergic reactions and transmission of infection. Also, while clinically utilized fibrin glue can effectively bond to wet tissue without a significant inflammatory response, it exhibits low strength of adhesion due to poor cohesive properties and can be challenging to apply as the polymerization time is difficult to control during placement (Lauto et al., 2008).

Another choice of natural tissue glues is collagen-based adhesives, which represent a relatively new class. Mechanism of adhesion mainly relies on ability of collagen to adsorb coagulation products in blood and trap them in its fibers and interstices. This results in adhesion to the wound by inducing platelet adhesion and activating coagulation factors (Farndale et al., 2004).

Two agents have been approved for use in the United States: FloSeal (Sulzer Spine-tech, Anaheim, CA) and Proceed (Fusion Medical Technologies, Mountain View, CA), which includes combination of bovine thrombin and bovine collagen (Ryou and Thompson, 2006). FloSeal is produced for hemostasis in vascular surgery, whereas Proceed is for prevention and treatment of CSF leaks.

Another novel collagen product is CoStasis (Cohesion Technologies, Inc., Palo Alto, CA), which uses a combination of autologous human plasma obtained from patients' blood and a mixture of bovine collagen and thrombin. It is used as a spray for surgical hemostasis and also for endoscopic control of gastrointestinal bleeding in which it provides significant improvement 
(Milkes et al., 2002). However, similar to all natural adhesives, due to bovine and porcine origin, there is a risk of allergic reaction and transmission of infection. Another drawback is the swelling with tissue similar to PEG hydrogel systems.

Another family of commercially available natural adhesives and sealants for clinical use is gelatin-glutaraldehyde systems, which undergo crosslinking reaction upon exposure to proper cross-linking agents. Gelatin is a biocompatible and bioabsorbable material and forms gels and films, which are flexible, strong, and transparent. However, in order to be used within physiological systems and due to their low stability in aqueous environment, gelatin networks need to be cross-linked. It was shown that high adhesive and tensile strength are achieved when gelatin is photochemically cross-linked (Elvin et al., 2010).

One of the adhesives of this type is gelatin-resorcin-formaldehyde/glutaraldehyde (GRF or GRFG). Through polycondensation reaction, aldehyde cross-links gelatin chains and forms bonds with amine groups of proteins. Currently, there is one such compound approved in the United States called BioGlue (CryoLife, Inc., Kennesaw, GA), which is a combination of bovine albumin and glutaraldehyde glue, used in nephron sparing surgery and aortic dissection (Hidas et al., 2006; Küçükaksu et al., 2000).

ProGel $^{\circledR}$ pleural air leak sealant is another type of adhesive that circumvents the use of glutaraldehyde, as it contains human albumin that is cross-linked with NHS end group-functionalized PEG. This sealant is approved to seal air leaks on lung tissue after surgery (Kobayashi et al., 2001). However, as for GRFG glues, similar safety concerns about using aldehyde-containing products have limited their wide utilization (Spotnitz and Burks, 2008). Macrophage phagocytosis degrades the adhesives, which starts 56 days after sealing air leaks in lung surgery, yet the degradation is slow, and only $20 \%$ of the glue is degraded after 6 months (Nomori et al., 1999). Another disadvantage is the requirement of preheating to $45^{\circ} \mathrm{C}$ before the application (Albes et al., 1993).

\subsection{BIOINSPIRED STRATEGIES}

Biological organisms produce highly sophisticated dry and underwater adhesives in remarkable diversity. Driven by the stringent natural selection process, physical or chemical demands occurring in a particular environment are met by elegant designs that are assembled from various components in a hierarchical organization across nano- to centimeter length scales. Furthermore, biological adhesives are usually noninvasive 
and highly economical in amount. These properties of biological adhesives inspire novel synthetic technologies and more efficient engineering principles, as the performance of them outperforms their man-made counterparts. In this regard, engineering new types of adhesives has been shaped around hybridization of natural design principles with advances in the synthetic technologies. This approach is principally advantageous for developing flexible and chemically well-defined adhesives with optimized material performance based on the demand in the medical and surgical applications. Besides, the use of a synthetic backbone with well-defined chemistry offers minimum batch-to-batch variation compared to natural adhesive extracts.

Underwater adhesion of mussels has become a valuable source of inspiration for developing new types of adhesive materials (Lee et al., 2011; Waite et al., 2005). Mussels are nonmotile organisms that cling themselves onto underwater rocks, wood, and ship hulls, even in the highly challenging intertidal zones of the seashores (Bre et al., 2013). The adhesion capacity of mussels comprehends virtually all types of low- and high-energy organic and inorganic surfaces, including superhydrophobic surfaces (Crisp et al., 1985; Kang et al., 2010). Currently, there is no synthetic glue that can bond to such a broad variety of surface types. In order to achieve this, mussels produce a special polyphenolic adhesive containing hierarchically organized proteins with varying content of 3,4-dihydroxy-L-phenylalanine (Dopa) residues (Cha et al., 2008; Papov et al., 1995; Zhao and Waite, 2006). Spatiotemporal evolution of this residue within the wet adhesive precursor plays a predominant role in mussel adhesion (Wilker, 2010). Catechol side chain of Dopa can form strong coordination complexes with metals and metal oxides, which drives the adhesion on such surfaces (Lee et al., 2007a). Hydroxyl groups on catechol can mediate hydrogen bonds with polar organic surfaces. Hydrophobic interaction is also a major contributor to the bonding to different surfaces. Furthermore, Dopa residues can undergo reversible and irreversible covalent couplings within the adhesive bulk, which significantly contribute to the cohesive and self-healing characters of the mussel glue (Ceylan et al., 2013b; Harrington et al., 2010; Monahan and Wilker, 2004; Xu et al., 2012). For an in-depth discussion of mussel adhesion, interested readers are directed to several excellent reviews (Ceylan et al., 2013a; Lee et al., 2011). In summary, versatility of the substrates enabled by Dopa-mediated adhesion chemistry and its biocompatible and water-resistant properties have motivated many researchers for developing mussel-inspired synthetic adhesives for biomedical applications. In addition, Dopa has a very simple chemical 
structure that can be easily grafted onto synthetic systems (Ceylan et al., 2011; Xu et al., 2012). Consequently, recapitulation of various functionalities in a Dopa-functionalized base adhesive can enable multifunctional complex designs with superior material performance. For example, Dopa-mediated adhesion was successfully exploited for functionalization of cardiovascular stent and bone implant surfaces with extracellular matrix-mimetic microenvironment actively interacting with the cells and directing their behavior (Ceylan et al., 2011, 2012, 2014). Another mussel-inspired, Dopa-mimetic unit molecule, dopamine, undergoes self-assembly and autopolymerization reaction in water that results in polydopamine (Hong et al., 2012). Any type of surface can be coated with polydopamine by simply dipping it into dopamine solution at $\mathrm{pH}$ approximately 8.5 (Kang et al., 2012; Lee et al., 2007a). Polydopamine coating also allows for secondary modifications through coupling to nucleophiles (Lee et al., 2009a). Dopa-mediated coating can mediate bone-like hydroxyapatite crystallization under physiologically simulated ionic conditions, thereby increasing the biocompatibility and osseointegration of bone implants (Ceylan et al., 2014; Ryu et al., 2010). Catecholfunctionalized chitosan/pluronic thermoresponsive and injectable hydrogels were utilized as hemostatic agents (Ryu et al., 2011). Dopa-grafted fourarmed PEG hydrogel was applied to transplant pancreatic islets in a murine model where no suture was necessary for the placement of the islets (Brubaker et al., 2010).

Sandcastle worm (Phragmatopoma californica) is another inspirational organism for developing underwater adhesives. It is a polychaete worm that secretes cement to build tube reef by gluing sand particles to each other. The glue is composed of a mixture of polyacidic and polybasic proteins and $\mathrm{Mg}^{2+}$ and $\mathrm{Ca}^{2+}$ ions (Zhao et al., 2005). Foamy structure and waterborne underwater adhesive capability of the cement is explained by complex coacervation of oppositely charged proteins and divalent cations, which exhibit electrostatic interactions at physiological pH (Stewart et al., 2004). Sandcastle worm glue analogs have been synthesized by different approaches, one of which is synthesis by incorporating similar molar ratios of phosphate, primary amine, and catechol side chains to native proteins, PC1 and PC3. Mixing of these protein analogs results in complex coacervation, which is able to bond wet cortical bone specimens (Shao et al., 2009). In another example, Mann et al. used coacervate adhesive to seal fetal membrane patches in in vitro model of fetoscopic defect (Mann et al., 2012). In this study, nontoxic, complex coacervate was formed by mixing poly(acrylamide-co-aminopropyl methacrylamide)-PEG-dA with poly(MOEP-co-DMA)-PEG-dA, which contains a certain ratio of $\mathrm{Ca}^{2+}$ to phosphate side chains in conjunction with 
$1 \mathrm{wt} \%$ nanosilica fillers that increased the efficacy. This system effectively sealed the defect in an aqueous environment. Sealing ability and nontoxic nature of the developed adhesives inspired from complex coacervation seem to make it a possible strategy promising for clinical applications, yet further studies in animal models are required to evaluate the efficacy and durability of bioinspired adhesives. Unique underwater adaptations of other aquatic organisms also offer potential opportunities and novel inspirations for the purpose of developing advanced adhesives for biomedical and surgical applications.

Gecko-inspired adhesives represent the most important class of bioinspired dry adhesives. Gecko's foot has a complex and hierarchical organization of keratinous hairs, called setae, and its projections, which make up the adhesive arrays and provide adhesive properties to vertical surfaces with varying roughness (Ruibal and Ernst, 1965). Climbing up on vertical surfaces requiring strong attachment and rapid detachment is provided by adhesion/friction forces between surface and gecko's foot. Van der Waals forces also play a driving role in the adhesion, which is not strongly affected by the actual surface chemistry (Autumn et al., $2000,2002)$. On the other hand, gecko adhesion is reduced dramatically underwater (Sun et al., 2005).

Gecko foot nanostructure is an inspiration source for development of dry adhesives for skin patch applications and wound dressings. Design and fabrication of such adhesives that stick to skin with enhanced durability and repeatable use over long periods of time by taking different properties of wounded and aged skin into consideration are vital for skin adhesive applications. It is therefore ideal for skin and wound patches to maintain moisture, provide antimicrobial effect, help healing process, and not cause any trauma upon removal (Rippon et al., 2007; Kwak et al., 2011). Despite the remarkable success of Geckoinspired adhesives for dry conditions, it needs further modifications for wet adhesions. A prominent strategy introduced a hybrid system inspired from both mussel and gecko adhesions. Using poly(dopamine methacrylamide-comethoxyethyl acrylate), a reversible dry/wet adhesive platform was developed through combining mussel-mimetic Dopa adhesion with gecko-mimetic polydimethylsiloxane pillars (Lee et al., 2007b). Polymer nanopillars were produced and coated with a thin layer of a synthetic polymer that provides wet adhesion by mimicking proteins found in mussel holdfasts (Mahdavi et al., 2008). Due to having nanostructure and mussel-mimetic polymer, it showed reversible and effective adhesion in both wet and dry conditions. For developing effective tissue adhesives inspired from gecko footpad, further studies 
are necessary to provide wet adhesion, which is one of the most important requirements for strong tissue adhesion. Developing nanostructured surfaces combined with thin film coatings for underwater adhesion is a promising strategy for further studies and translation into biomedical applications.

\subsection{NANOENABLED ADHESIVES}

Adhesion of hydrogels through nanoparticle-embedded interfaces has emerged as a recent concept (Fig. 8.3) (Meddahi-Pellé et al., 2014; Rose et al., 2014). Network chains are adsorbed on nanoparticles at the interface of the bonding gels, or tissue parts, such as liver and heart by gently pressing onto one another. Therefore, nanoparticles act as connectors between the pieces and assure adhesion. Under mechanical stress, polymer chains reorganize and dissipate energy that withstands the rupture. Application of the adhesive is also quite straightforward: An arbitrary drop of nanoparticle dispersion is simply casted onto one substrate (either hydrogel or tissue part) and then the other substrate is pressed against the adsorbed substrate for less than a minute. Animal experiments suggest no wound leakage, infection, or inflammatory reactions with nanoparticle-mediated wound closure, which is comparable with suturing. On the other hand, the wound edges fail to bond correctly. Liver, heart, and skin bonding was demonstrated within this context (Meddahi-Pellé et al., 2014). Self-assembled mussel-mimetic nanofibrous networks that emulate the extracellular matrix via conjugated ligands represent another state-of-the-art class of nanoenabled adhesives that have been mostly applied as regenerative implant coatings, such as cardiovascular stents and bone implants (Ceylan et al., 2011, 2012, 2013a, 2014).

\subsection{CONCLUSION AND FUTURE PROSPECTS}

There are only few tissue adhesives that exhibit multiple functionalities in addition to bonding. In particular, guiding proper tissue regeneration at the wound/incision site would greatly aid in accelerated patient recovery as well as lesser scar tissue formation. Another significant improvement will be antibacterial adhesives, as the infection is becoming a major concern in surgical intervention ( $\mathrm{Li}$ et al., 2011). Biomimetic materials are expected to continue to be a central theme by 
(a)

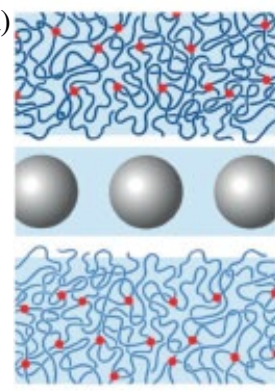

(b)

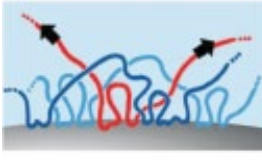

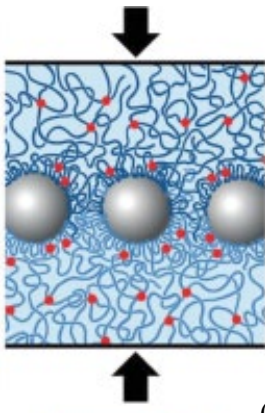

(d) $\mathrm{SiO}_{2} \mathrm{NP}$ Ethicon suture Dermabond
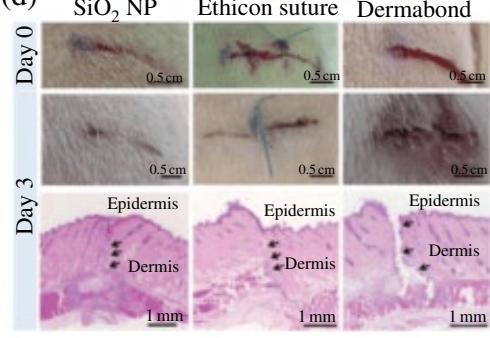

(e)

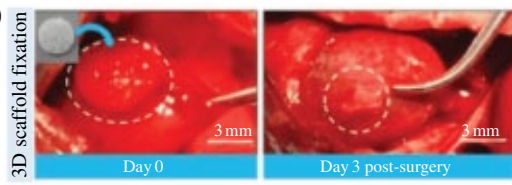

FIGURE 8.3 Nanoparticles can function as soft tissue adhesives. (a) Schematic illustration of nanoparticle-mediated bonding of polymer networks. Network chains are adsorbed on nanoparticles, via squeezing (see the arrows), at the interface of the bonding gels. Source: Rose et al. (2014). Reproduced with permission from John Wiley \& Sons, Inc. and Nature Publishing Group. (b) Particle adsorption creates anchorage points to the gel networks. Under stress, one of the chains that detaches from a particle surface, can cause energy dissipation, thereby allowing for large deformations. (c) Bonding two calf liver parts using TM50 silica solution casting in between them and then gently pressing for $30 \mathrm{~s}$. (d) In vivo application of $\mathrm{SiO}_{2}$ nanoparticles to bond the dorsal skin in a rat model. An arbitrary drop of nanoparticle dispersion is simply casted onto the wound edges and then the two ends are gently pressed for about $1 \mathrm{~min}$. Histological examination on day 3 shows no wound leakages, infection, or inflammatory reactions with nanoparticle-mediated wound closure, which is comparable with suturing. On the other hand, the wound edges fail to bond correctly. Source: Meddahi-Pellé et al. (2014). Reproduced with permission from John Wiley \& Sons, Inc. and Nature Publishing Group. (e) Implantation of a 3D scaffold to a beating rat heart using Ludox TM50 silica nanoparticles (Meddahi-Pellé et al., 2014). The scaffold remains attached to the heart at the end of 3 days.

converging disciplines to reconstitute adaptive characteristics of biological systems in synthetic adhesives with nanoscale adaptations. Although natural adhesives exhibit exceptional performance under highly abrasive conditions, the high cost of obtaining adhesives from their original natural sources and high batch-to-batch variation encourages alternative biomimetic solutions in synthetic constructs (Table 8.1). 


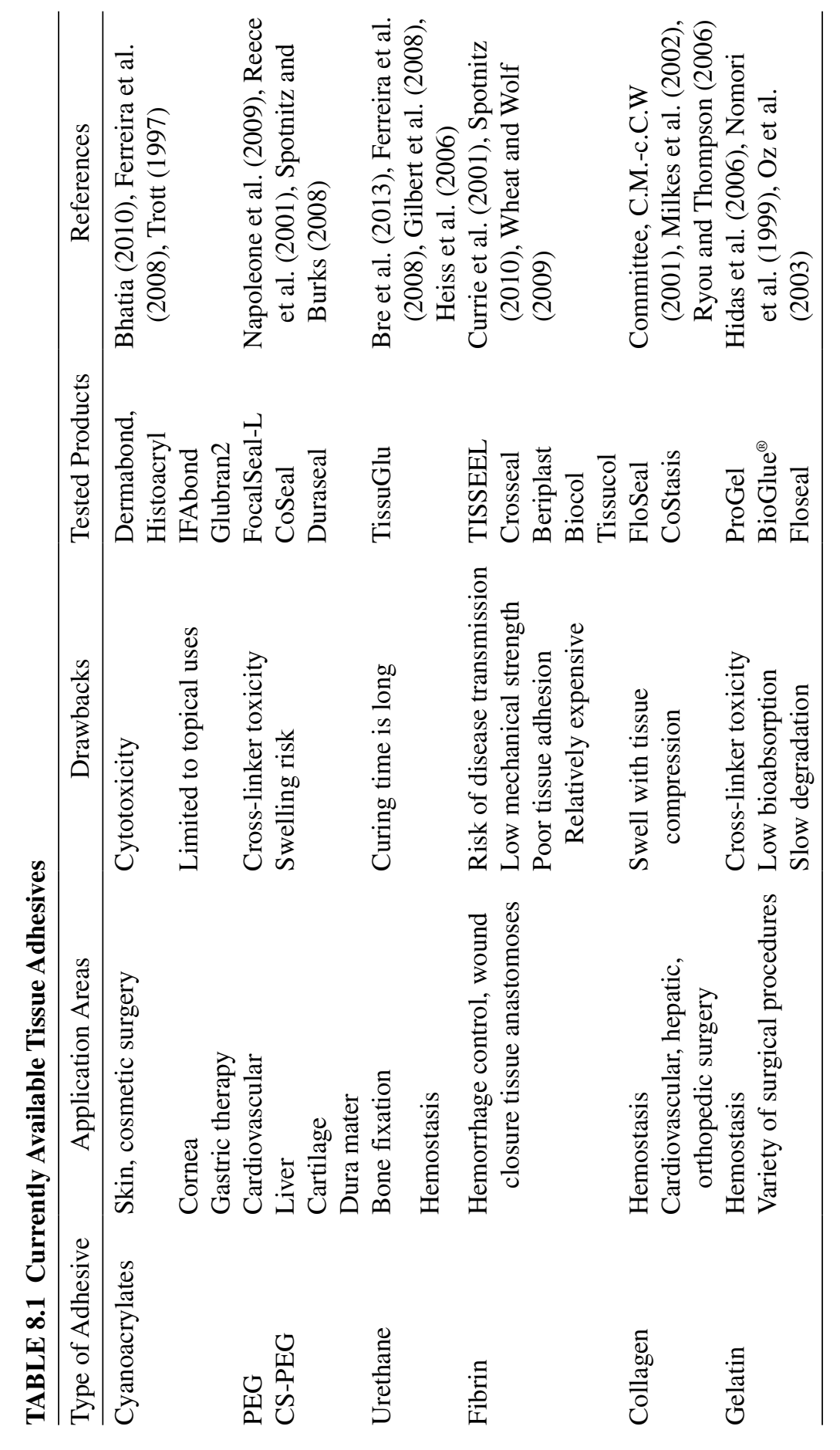




\section{REFERENCES}

Agarwal, S., Beckman, E.J., Buckley, M., and Zhang, J. (2007). Medical adhesive and methods of tissue adhesion, US 7264823 B2 (Google Patents).

Albes, J.M., Krettek, C., Hausen, B., Rohde, R., Haverich, A., and Borst, H.-G. (1993). Biophysical properties of the gelatin-resorcin-formaldehyde/glutaraldehyde adhesive. The Annals of Thoracic Surgery 56, 910-915.

Annabi, N., Tamayol, A., Shin, S.R., Ghaemmaghami, A.M., Peppas, N.A., and Khademhosseini, A. (2014). Surgical materials: current challenges and nanoenabled solutions. Nano Today 9, 574-589.

Autumn, K., Liang, Y.A., Hsieh, S.T., Zesch, W., Chan, W.P., Kenny, T.W., Fearing, R., and Full, R.J. (2000). Adhesive force of a single gecko foot-hair. Nature 405, 681-685.

Autumn, K., Sitti, M., Liang, Y.A., Peattie, A.M., Hansen, W.R., Sponberg, S., Kenny, T.W., Fearing, R., Israelachvili, J.N., and Full, R.J. (2002). Evidence for van der Waals adhesion in gecko setae. Proceedings of the National Academy of Sciences of the United States of America 99, 12252-12256.

Avila, G., Misch, K., Galindo-Moreno, P., and Wang, H.L. (2009). Implant surface treatment using biomimetic agents. Implant Dentistry 18, 17-26.

Bhatia, S.K. (2010). Biomaterials for clinical applications (New York: Springer).

Bouten, P.J.M., Zonjee, M., Bender, J., Yauw, S.T.K., van Goor, H., van Hest, J.C.M., and Hoogenboom, R. (2014). The chemistry of tissue adhesive materials. Progress in Polymer Science 39, 1375-1405.

Bre, L.P., Zheng, Y., Pego, A.P., and Wang, W. (2013). Taking tissue adhesives to the future: from traditional synthetic to new biomimetic approaches. Biomaterials Science 1, 239-253.

Brennan, M. (1991). Fibrin glue. Blood Reviews 5, 240-244.

Brubaker, C.E., Kissler, H., Wang, L.-J., Kaufman, D.B., and Messersmith, P.B. (2010). Biological performance of mussel-inspired adhesive in extrahepatic islet transplantation. Biomaterials 31, 420-427.

Ceylan, H., Tekinay, A.B., and Guler, M.O. (2011). Selective adhesion and growth of vascular endothelial cells on bioactive peptide nanofiber functionalized stainless steel surface. Biomaterials 32, 8797-8805.

Ceylan, H., Kocabey, S., Tekinay, A.B., and Guler, M.O. (2012). Surface-adhesive and osteogenic self-assembled peptide nanofibers for bioinspired functionalization of titanium surfaces. Soft Matter 8, 3929-3937.

Ceylan, H., Tekinay, A.B., and Guler, M.O. (2013a). Mussel-inspired Adhesive Interfaces for Biomedical Applications. In Biological and biomimetic adhesives: challenges and opportunities (P. Flammang, R. Santos, N. Aldred, S. Gorb, eds., Cambridge: The Royal Society of Chemistry), pp. 103-116. 
Ceylan, H., Urel, M., Erkal, T.S., Tekinay, A.B., Dana, A., and Guler, M.O. (2013b). Mussel inspired dynamic cross-linking of self-healing peptide nanofiber network. Advanced Functional Materials 23, 2081-2090.

Ceylan, H., Kocabey, S., Unal Gulsuner, H., Balcik, O.S., Guler, M.O., and Tekinay, A.B. (2014). Bone-like mineral nucleating peptide nanofibers induce differentiation of human mesenchymal stem cells into mature osteoblasts. Biomacromolecules 15, 2407-2418.

Cha, H.J., Hwang, D.S., and Lim, S. (2008). Development of bioadhesives from marine mussels. Biotechnology Journal 3, 631-638.

Committee, C.M.-c.C.W. (2001). A novel collagen-based composite offers effective hemostasis for multiple surgical indications: results of a randomized controlled trial. Surgery 129, 445-450.

Crisp, D.J., Walker, G., Young, G.A., and Yule, A.B. (1985). Adhesion and substrate choice in mussels and barnacles. Journal of Colloid and Interface Science 104, 40-50.

Currie, L.J., Sharpe, J.R., and Martin, R. (2001). The use of fibrin glue in skin grafts and tissue-engineered skin replacements. Plastic and Reconstructive Surgery 108, 1713-1726.

Elvin, C.M., Vuocolo, T., Brownlee, A.G., Sando, L., Huson, M.G., Liyou, N.E., Stockwell, P.R., Lyons, R.E., Kim, M., Edwards, G.A., et al. (2010). A highly elastic tissue sealant based on photopolymerised gelatin. Biomaterials 31, 8323-8331.

Farndale, R., Sixma, J., Barnes, M., and De Groot, P. (2004). The role of collagen in thrombosis and hemostasis. Journal of Thrombosis and Haemostasis 2, 561-573.

Ferreira, P., Pereira, R., Coelho, J.F.J., Silva, A.F.M., and Gil, M.H. (2007). Modification of the biopolymer castor oil with free isocyanate groups to be applied as bioadhesive. International Journal of Biological Macromolecules $40,144-152$.

Ferreira, P., Coelho, J.F.J., and Gil, M.H. (2008). Development of a new photocrosslinkable biodegradable bioadhesive. International Journal of Pharmaceutics 352, 172-181.

Gilbert, T.W., Badylak, S.F., Gusenoff, J., Beckman, E.J., Clower, D.M., Daly, P., and Rubin, J.P. (2008). Lysine-derived urethane surgical adhesive prevents seroma formation in a canine abdominoplasty model. Plastic and Reconstructive Surgery $122,95-102$.

Gittens, R.A., Olivares-Navarrete, R., Schwartz, Z., and Boyan, B.D. (2014). Implant osseointegration and the role of microroughness and nanostructures: lessons for spine implants. Acta Biomaterialia 10, 3363-3371.

Harrington, M.J., Masic, A., Holten-Andersen, N., Waite, J.H., and Fratzl, P. (2010). Iron-clad fibers: a metal-based biological strategy for hard flexible coatings. Science 328, 216-220. 
Heiss, C., Kraus, R., Schluckebier, D., Stiller, A.-C., Wenisch, S., and Schnettler, R. (2006). Bone adhesives in trauma and orthopedic surgery. European Journal of Trauma 32, 141-148.

Hidas, G., Kastin, A., Mullerad, M., Shental, J., Moskovitz, B., and Nativ, O. (2006). Sutureless nephron-sparing surgery: use of albumin glutaraldehyde tissue adhesive (BioGlue). Urology 67, 697-700.

Hong, S., Na, Y.S., Choi, S., Song, I.T., Kim, W.Y., and Lee, H. (2012). Non-covalent self-assembly and covalent polymerization co-contribute to polydopamine formation. Advanced Functional Materials 22, 4711-4717.

Kang, S.M., You, I., Cho, W.K., Shon, H.K., Lee, T.G., Choi, I.S., Karp, J.M., and Lee, H. (2010). One-step modification of superhydrophobic surfaces by a mussel-inspired polymer coating. Angewandte Chemie International Edition 49, 9401-9404.

Kang, S.M., Hwang, N.S., Yeom, J., Park, S.Y., Messersmith, P.B., Choi, I.S., Langer, R., Anderson, D.G., and Lee, H. (2012). One-step multipurpose surface functionalization by adhesive catecholamine. Advanced Functional Materials 22, 2949-2955.

Kobayashi, H., Sekine, T., Nakamura, T., and Shimizu, Y. (2001). In vivo evaluation of a new sealant material on a rat lung air leak model. Journal of Biomedical Materials Research 58, 658-665.

Küçükaksu, D.S., Akgül, A., Çağli, K., and Taşdemir, O. (2000). Beneficial effect of BioGlue ${ }^{\circledR}$ surgical adhesive in repair of iatrogenic aortic dissection. Texas Heart Institute Journal 27, 307.

Kull, S., Martinelli, I., Briganti, E., Losi, P., Spiller, D., Tonlorenzi, S., and Soldani, G. (2009). Glubran2 surgical glue: in vitro evaluation of adhesive and mechanical properties. Journal of Surgical Research 157, e15-e21.

Kwak, M.K., Jeong, H.-E., and Suh, K.Y. (2011). Rational design and enhanced biocompatibility of a dry adhesive medical skin patch. Advanced Materials 23, 3949-3953.

Lauto, A., Mawad, D., and Foster, L.J.R. (2008). Adhesive biomaterials for tissue reconstruction. Journal of Chemical Technology \& Biotechnology 83, 464-472.

Lee, H., Dellatore, S.M., Miller, W.M., and Messersmith, P.B. (2007a). Musselinspired surface chemistry for multifunctional coatings. Science 318, 426-430.

Lee, H., Lee, B.P., and Messersmith, P.B. (2007b). A reversible wet/dry adhesive inspired by mussels and geckos. Nature 448, 338-341.

Lee, H., Rho, J., and Messersmith, P.B. (2009a). Facile conjugation of biomolecules onto surfaces via mussel adhesive protein inspired coatings. Advanced Materials 21, 431-434.

Lee, S., Pham, A.M., Pryor, S.G., Tollefson, T., and Sykes, J.M. (2009b). Efficacy of Crosseal fibrin sealant (human) in rhytidectomy. Archives of Facial Plastic Surgery $11,29-33$. 
Lee, B.P., Messersmith, P.B., Israelachvili, J.N., and Waite, J.H. (2011). Musselinspired adhesives and coatings. Annual Review of Materials Research 41, 99-132.

Lees, W.A. (1979). The science of acrylic adhesives. British Polymer Journal 11, 64-71.

Leggat, P.A., Kedjarune, U., and Smith, D.R. (2004). Toxicity of cyanoacrylate adhesives and their occupational impacts for dental staff. Industrial Health 42, 207-211.

Li, W.-R., Xie, X.-B., Shi, Q.-S., Duan, S.-S., Ouyang, Y.-S., and Chen, Y.-B. (2011). Antibacterial effect of silver nanoparticles on Staphylococcus aureus. Biometals 24, 135-141.

Liu, Y., Li, J.P., Hunziker, E.B., and de Groot, K. (2006). Incorporation of growth factors into medical devices via biomimetic coatings. Philosophical Transactions. Series A, Mathematical, Physical, and Engineering Sciences $364,233-248$.

Mahdavi, A., Ferreira, L., Sundback, C., Nichol, J.W., Chan, E.P., Carter, D.J.D., Bettinger, C.J., Patanavanich, S., Chignozha, L., Ben-Joseph, E., et al. (2008). A biodegradable and biocompatible gecko-inspired tissue adhesive. Proceedings of the National Academy of Sciences of the United States of America 105, 2307-2312.

Maluf, F., Sakai, P., Ishioka, S., and Matuguma, S.E. (2001). Endoscopic sclerosis versus cyanoacrylate endoscopic injection for the first episode of variceal bleeding: a prospective, controlled, and randomized study in Child-Pugh class C patients. Endoscopy 33, 421-427.

Mann, L.K., Papanna, R., Moise Jr, K.J., Byrd, R.H., Popek, E.J., Kaur, S., Tseng, S.C.G., and Stewart, R.J. (2012). Fetal membrane patch and biomimetic adhesive coacervates as a sealant for fetoscopic defects. Acta Biomaterialia 8 , 2160-2165.

Meddahi-Pellé, A., Legrand, A., Marcellan, A., Louedec, L., Letourneur, D., and Leibler, L. (2014). Organ repair, hemostasis, and in vivo bonding of medical devices by aqueous solutions of nanoparticles. Angewandte Chemie International Edition 53, 6369-6373.

Mehdizadeh, M. and Yang, J. (2013). Design strategies and applications of tissue bioadhesives. Macromolecular Bioscience 13, 271-288.

Milkes, D.E., Friedland, S., Lin, O.S., Reid, T.R., and Soetikno, R.M. (2002). A novel method to control severe upper GI bleeding from metastatic cancer with a hemostatic sealant: the CoStasis surgical hemostat. Gastrointestinal Endoscopy $55,735-740$.

Monahan, J. and Wilker, J.J. (2004). Cross-linking the protein precursor of marine mussel adhesives: bulk measurements and reagents for curing. Langmuir 20, 3724-3729. 
Mutignani, M., Iacopini, F., Dokas, S., Larghi, A., Familiari, P., Tringali, A., and Costamagna, G. (2006). Successful endoscopic closure of a lateral duodenal perforation at ERCP with fibrin glue. Gastrointestinal Endoscopy $63,725-727$.

Napoleone, C.P., Valori, A., Crupi, G., Ocello, S., Santoro, F., Vouhé, P., Weerasena, N., and Gargiulo, G. (2009). An observational study of $\mathrm{CoSeal}^{\circledR}$ for the prevention of adhesions in pediatric cardiac surgery. Interactive Cardiovascular and Thoracic Surgery 9, 978-982.

Nomori, H., Horio, H., Morinaga, S., and Suemasu, K. (1999). Gelatin-resorcinolformaldehyde-glutaraldehyde glue for sealing pulmonary air leaks during thoracoscopic operation. The Annals of Thoracic Surgery 67, 212-216.

Oz, M.C., Rondinone, J.F., and Shargill, N.S. (2003). Floseal matrix. Journal of Cardiac Surgery 18, 486-493.

Páez, J.M.G., Herrero, E.J., Rocha, A., Maestro, M., Castillo-Olivares, J.L., Millan, I., Sanmartin, A.C., and Cordon, A. (2004). Comparative study of the mechanical behaviour of a cyanoacrylate and a bioadhesive. Journal of Materials Science: Materials in Medicine 15, 109-115.

Papov, V.V., Diamond, T.V., Biemann, K., and Waite, J.H. (1995). Hydroxyargininecontaining polyphenolic proteins in the adhesive plaques of the marine mussel Mytilus edulis. Journal of Biological Chemistry 270, 20183-20192.

Rabago, L., Ventosa, N., Castro, J., Marco, J., Herrera, N., and Gea, F. (2002). Endoscopic treatment of postoperative fistulas resistant to conservative management using biological fibrin glue. Endoscopy 34, 632-638.

Reece, T.B., Maxey, T.S., and Kron, I.L. (2001). A prospectus on tissue adhesives. The American Journal of Surgery 182, S40-S44.

Report S190. (2012). Worldwide surgical sealants, glues, wound closure and antiadhesion markets, 2010-2017. (Foothill Ranch, CA: MedMarket Diligence, LLC).

Richards, R.G., Moriarty, T.F., Miclau, T., McClellan, R.T., and Grainger, D.W. (2012). Advances in biomaterials and surface technologies. Journal of Orthopaedic Trauma 26, 703-707.

Rippon, M., White, R., and Davies, P. (2007). Skin adhesives and their role in wound dressings. WOUNDS UK 3, 76.

Rose, S., Prevoteau, A., Elziere, P., Hourdet, D., Marcellan, A., and Leibler, L. (2014). Nanoparticle solutions as adhesives for gels and biological tissues. Nature 505, 382-385.

Ruibal, R. and Ernst, V. (1965). The structure of the digital setae of lizards. Journal of Morphology 117, 271-293.

Ryan, B.M., Stockbrugger, R.W., and Ryan, J.M. (2004). A pathophysiologic, gastroenterologic, and radiologic approach to the management of gastric varices. Gastroenterology 126, 1175-1189. 
Ryou, M. and Thompson, C.C. (2006). Tissue adhesives: a review. Techniques in Gastrointestinal Endoscopy 8, 33-37.

Ryu, J., Ku, S.H., Lee, H., and Park, C.B. (2010). Mussel-inspired polydopamine coating as a universal route to hydroxyapatite crystallization. Advanced Functional Materials 20, 2132-2139.

Ryu, J.H., Lee, Y., Kong, W.H., Kim, T.G., Park, T.G., and Lee, H. (2011). Catechol-functionalized chitosan/pluronic hydrogels for tissue adhesives and hemostatic materials. Biomacromolecules 12, 2653-2659.

Sanders, L. and Nagatomi, J. (2014). Clinical applications of surgical adhesives and sealants. Critical Reviews in Biomedical Engineering 42, 271-292.

Seewald, S., Sriram, P.V.J., Naga, M., Fennerty, M.B., Boyer, J., Oberti, F., and Soehendra, N. (2002). Cyanoacrylate glue in gastric variceal bleeding. Endoscopy 34, 926-932.

Shao, H., Bachus, K.N., and Stewart, R.J. (2009). A water-borne adhesive modeled after the sandcastle glue of $P$. californica. Macromolecular Bioscience 9, 464-471.

Sharma, B., Fermanian, S., Gibson, M., Unterman, S., Herzka, D.A., Cascio, B., Coburn, J., Hui, A.Y., Marcus, N., Gold, G.E., et al. (2013). Human cartilage repair with a photoreactive adhesive-hydrogel composite. Science Translational Medicine 5, 167ra166.

Shazly, T.M., Artzi, N., Boehning, F., and Edelman, E.R. (2008). Viscoelastic adhesive mechanics of aldehyde-mediated soft tissue sealants. Biomaterials 29, 4584-4591.

Singer, A.J., Quinn, J.V., and Hollander, J.E. (2008). The cyanoacrylate topical skin adhesives. The American Journal of Emergency Medicine 26, 490-496.

Spotnitz, W. (2010). Fibrin sealant: past, present, and future: a brief review. World Journal of Surgery 34, 632-634.

Spotnitz, W.D. and Burks, S. (2008). Hemostats, sealants, and adhesives: components of the surgical toolbox. Transfusion 48, 1502-1516.

Stewart, R.J., Weaver, J.C., Morse, D.E., and Waite, J.H. (2004). The tube cement of Phragmatopoma californica: a solid foam. The Journal of Experimental Biology 207, 4727-4734.

Strehin, I., Nahas, Z., Arora, K., Nguyen, T., and Elisseeff, J. (2010). A versatile $\mathrm{pH}$ sensitive chondroitin sulfate-PEG tissue adhesive and hydrogel. Biomaterials 31, 2788-2797.

Sun, W., Neuzil, P., Kustandi, T.S., Oh, S., and Samper, V.D. (2005). The nature of the gecko lizard adhesive force. Biophysical Journal 89, L14-L17.

Trott, A.T. (1997). Cyanoacrylate tissue adhesives: an advance in wound care. JAMA 277, 1559-1560. 
Vote, B.J. and Elder, M.J. (2000). Cyanoacrylate glue for corneal perforations: a description of a surgical technique and a review of the literature. Clinical \& Experimental Ophthalmology 28, 437-442.

Waite, J.H., Andersen, N.H., Jewhurst, S., and Sun, C. (2005). Mussel adhesion: finding the tricks worth mimicking. The Journal of Adhesion 81, 297-317.

Wheat, J.C. and Wolf Jr, J.S. (2009). Advances in bioadhesives, tissue sealants, and hemostatic agents. Urologic Clinics of North America 36, 265-275.

Wilker, J.J. (2010). The iron-fortified adhesive system of marine mussels. Angewandte Chemie International Edition 49, 8076-8078.

Xu, H., Nishida, J., Ma, W., Wu, H., Kobayashi, M., Otsuka, H., and Takahara, A. (2012). Competition between oxidation and coordination in cross-linking of polystyrene copolymer containing catechol groups. ACS Macro Letters 1, 457-460.

Yang, S.Y., O’Cearbhaill, E.D., Sisk, G.C., Park, K.M., Cho, W.K., Villiger, M., Bouma, B.E., Pomahac, B., and Karp, J.M. (2013). A bio-inspired swellable microneedle adhesive for mechanical interlocking with tissue. Nature Communications 4, 1702.

Zhao, H. and Waite, J.H. (2006). Linking adhesive and structural proteins in the attachment plaque of Mytilus californianus. Journal of Biological Chemistry 281, 26150-26158.

Zhao, H., Sun, C.J., Stewart, R.J., and Waite, J.H. (2005). Cement proteins of the tube-building polychaete Phragmatopoma californica. Journal of Biological Chemistry 280, 42938-42944. 